\title{
Twenty-seven-gauge vitrectomy for combined tractional and rhegmatogenous retinal detachment involving the macula associated with proliferative diabetic retinopathy
}

\author{
Yousef J. Cruz-Iñigo ${ }^{1 *}$ and María H. Berrocal ${ }^{1,2}$
}

\begin{abstract}
Background: To report our experience using 27-gauge pars plana vitrectomy (PPV) system for treating patients with combined tractional and rhegmatogenous retinal detachments (CTRRD) involving the macula associated with proliferative diabetic retinopathy (PDR).

Methods: Retrospective noncomparative interventional cases series of 12 patients with CTRRD associated with PDR who underwent 3-port, transconjunctival 27-gauge PPV by a single surgeon. Main outcome measures were change in Snellen best corrected visual acuity (BCVA) and occurrence of intra- and post-operative complications.

Results: Twelve eyes from 12 patients (9 men and 3 women) underwent 27-gauge PPV. Mean follow-up was 17 months (range 8-26 months). Preoperatively, BCVA of 20/400 or better was recorded in only 2 of 12 (16.7\%) eyes. Postoperatively, BCVA improved to 20/400 or better in 11 of $12(91.7 \%)$ eyes at 6 months $(P=0.001)$. At last follow-up, BCVA of 20/400 or better was recorded in 10 of $12(83.3 \%)$, in comparison to $2(16.7 \%)$ eyes at baseline $(P=0.004)$. The only intraoperative complication was an iatrogenic break in 1 eye (8.3\%). Postoperative complications included vitreous hemorrhage in 4 eyes (33.3\%) and transient ocular hypertension in 3 eyes (25.0\%). At final follow-up anatomic success was confirmed in all eyes.

Conclusion: The current study findings suggest that 27-gauge PPV is a safe and promising surgical technology for treating patients with CTRRD involving the macula associated with PDR. Smaller gauge instruments and higher cutting rates may facilitate the dissection and shaving of fibrovascular membranes, while minimizing intra- and postoperative complications.
\end{abstract}

Keywords: 27-Gauge vitrectomy system, Combined tractional and rhegmatogenous retinal detachments, Small gauge

\section{Background}

Transconjunctival microincision vitrectomy surgery (MIVS) rapidly gained acceptance following the introduction of 25- and 23-gauge systems. Important

\footnotetext{
*Correspondence: yousef.cruz@upr.edu

1 Department of Ophthalmology, Río Piedras Medical Center, University of Puerto Rico, San Juan 00909, Puerto Rico

Full list of author information is available at the end of the article
}

advantages over traditional 20-gauge surgery were faster wound healing, decreased conjunctival scarring, shorter operating time, reduced postoperative inflammation, reduced corneal astigmatism, and improved patient comfort with earlier visual recovery [1-3]. Aiming to enhance these advantages while minimizing the risk of hypotony, choroidal detachment and postoperative endophthalmitis, in 2010 Oshima et al. [4] described the use of the 27 -gauge vitrectomy system. Since the introduction of 
this technology, only few postoperative complications have been reported including vitreous hemorrhage (VH), transient ocular hypertension and transient hypotony [4-7].

Similar to earlier experiences with small-gauge systems, surgical indications for 27-gauge pars plana vitrectomy (PPV) surgery are rapidly expanding due to its effectiveness and safety profile. Initially used for treating macular cases of lower complexity and $\mathrm{VH}$ [4], 27-gauge PPV surgery is now being used for more complex posterior segment cases including primary rhegmatogenous retinal detachment with or without proliferative vitreoretinopathy (PVR) and diabetic tractional retinal detachment $[5,7]$. However, recent studies reporting surgical outcomes for combined tractional and rhegmatogenous detachment (CTRRD) associated to proliferative diabetic retinopathy (PDR) are limited to 20- or 23-gauge systems. These cases are considered one of the most complex diabetic surgeries as they require difficult techniques for removing fibrovascular tissue from the detached retina, closing retinal breaks and reattaching the retina while avoiding iatrogenic breaks. In the current study the experience using 27-gauge PPV system is reported for treating patients with CTRRD involving the macula associated with PDR.

\section{Methods}

This study is a retrospective, noncomparative, interventional case series. The medical records were reviewed for all patients who underwent 3-port, transconjunctival 27-gauge PPV for CTRRD secondary to PDR between January 1, 2014 and December 31, 2016. Patients were excluded if larger gauge equivalents were used or if the retinal detachment was not combined. Eyes undergoing concurrent cataract extraction were included.

All surgical procedures were performed by one surgeon (M.H.B.) under local anesthesia using the Constellation Vitrectomy 27+ Total Plus Pak vitrectomy system (Alcon Laboratories, Fort Worth, Texas, USA). Cannulas were inserted in the inferotemporal, superotemporal, and superonasal quadrants $3.0-4 \mathrm{~mm}$ posterior to the limbus. The conjunctiva and Tenon capsule were displaced over the sclera to avoid communication between the conjunctival and scleral entry sites. Trocar cannulas were inserted with an angled (less than 90 degrees to the sclera) approach. Core vitrectomy was performed in all cases using a cut rate of 7500 cuts per minute (cpm) and linear aspiration of $0-650 \mathrm{mmHg}$. Removal of all vitreous opacities and posterior hyaloid was then performed without the need of adjuvant intravitreal triamcinolone acetonide. Areas of fibrovascular proliferation were segmented and dissected with the 27-gauge vitrectomy probe. This was followed by panretinal photocoagulation with an endophotocoagulation probe. Fluid-air exchange, fluid-gas exchange (12-16\% perfluoropropane $\left[\mathrm{C}_{3} \mathrm{~F}_{8}\right]$ or $16-18 \%$ sulfur hexafluoride $\left.\left[\mathrm{SF}_{6}\right]\right)$, or silicone oil $(\mathrm{SO})$ tamponade (1000 centistokes) were performed as needed. At the conclusion of each case, a peripheral retinal examination was performed with scleral depression and widefield view to evaluate for retinal breaks. All sclerotomy sites were inspected after removal or cannulas.

Patient records were reviewed and the following data were collected: age, gender, past ocular history. In addition, the following pre- and post-operative findings were recorded: Snellen best corrected visual acuity (BCVA), intraocular pressure (IOP) measured with Goldmann applanation tonometer, slit-lamp biomicrosopy of anterior segment, fundoscopy and spectral-domain optical coherence tomography (OCT; Spectralis HRA + OCT; Heidelberg Engineering, Heidelberg, Germany). Postoperative evaluation and recording of findings were performed at 1-day, 1-week, 1-months, 3-months, 6-months, 12-months and, thereafter, at all subsequent followup visits. Preoperative surgical details were recorded including injection of intravitreal bevacizumab (IVB) of $12.5 \mathrm{mg}$ within 3-5 days prior to surgery. Also recorded, were intraoperative surgical details including use of air, gas, or SO tamponade (1000 centistoke); and total surgical time. Intraoperative complications including bleeding, iatrogenic retinal breaks, sclerotomy site leakage and suturing were also recorded. Postoperative complications including ocular hypertension, hypotony, $\mathrm{VH}$, endophthalmitis, retinal and/or choroidal detachment were documented if present. $\mathrm{VH}$ was classified as early postoperative (VH fewer than 6 weeks from surgery but not present on postoperative day 1 ), delayed postoperative (VH 6 weeks or more from surgery), or severe persistent (nonclearing for more than 6 weeks and present since postoperative day 1). Ocular hypertension was defined as an IOP of $25 \mathrm{mmHg}$ or more at any visit while hypotony was defined as an IOP of $6 \mathrm{mmHg}$ or less. The primary outcomes measures were change in BCVA, retinal re-attachment and presence of intra- and post-operative complications.

\section{Results}

Twelve eyes from 12 patients ( 9 men and 3 women) with history of PDR secondary to type 2 diabetes mellitus were referred to our clinic due to CTRRD involving the macula (Table 1). Mean age at first evaluation and surgical intervention was 53 years (standard deviation 7 years, range 38-72 years). Mean follow-up was 17 months (range 8-26 months). Ocular history was only relevant for pseudophakia in 3 eyes. Remaining 9 eyes were phakic. At first evaluation, funduscopic exam and macular OCT revealed broad fibrovascular membranes along 
Table 1 Baseline characteristics, pre- and post-operative visual acuity outcomes following 27-gauge pars plana vitrectomy for combined tractional and rhegmatogenous retinal detachment

\begin{tabular}{|c|c|c|c|c|c|c|}
\hline \multirow[t]{3}{*}{ Case } & \multirow[t]{3}{*}{ Age (years) } & \multirow[t]{3}{*}{ Gender } & \multirow[t]{3}{*}{ Duration of follow-up (months) } & \multicolumn{3}{|c|}{ Best-corrected visual acuity } \\
\hline & & & & \multirow[t]{2}{*}{ Pre-operative } & \multicolumn{2}{|c|}{ Post-operative } \\
\hline & & & & & 6 month & Last follow-up \\
\hline 1 & 54 & Female & 20 & $5 / 200$ & $20 / 400$ & $20 / 400$ \\
\hline 2 & 60 & Male & 15 & $20 / 100$ & $20 / 50$ & $20 / 50$ \\
\hline 3 & 58 & Male & 25 & $4 / 200$ & $1 / 200$ & $\mathrm{HM}$ \\
\hline 4 & 48 & Male & 26 & $3 / 200$ & $20 / 50$ & $20 / 40$ \\
\hline 5 & 64 & Male & 26 & $2 / 200$ & $20 / 50$ & $20 / 70$ \\
\hline 6 & 53 & Male & 16 & $3 / 200$ & $20 / 400$ & $20 / 400$ \\
\hline 7 & 50 & Female & 12 & $5 / 200$ & $20 / 100$ & $20 / 80$ \\
\hline 8 & 54 & Male & 8 & 20/200 & $20 / 100$ & $20 / 100$ \\
\hline 9 & 60 & Male & 13 & $5 / 200$ & $20 / 400$ & $20 / 400$ \\
\hline 10 & 52 & Male & 18 & $1 / 200$ & $20 / 400$ & $20 / 400$ \\
\hline 11 & 39 & Male & 13 & $\mathrm{HM}$ & $20 / 400$ & $3 / 200$ \\
\hline 12 & 49 & Female & 18 & $2 / 200$ & $20 / 200$ & $20 / 200$ \\
\hline
\end{tabular}

the arcades with adhesions in more than 2 sites causing a TRD with associated rhegmatogenous retinal detachment in all cases.

Adjuvant preoperative IVB was used in all cases. All patients underwent 27-gauge PPV surgery without the need conversion to a larger vitrectomy system or using bimanual techniques. Only, one case underwent concurrent cataract extraction and intraocular lens implantation at the time of vitrectomy. In addition, one case required temporary intraoperative tamponade with perfluorocarbon liquid to help flattened the retina (patient 2 in Table 1). All cases were completed without the need of performing retinotomies or retinectomies. Mean operative time was $50 \mathrm{~min}$ (standard deviation $5 \mathrm{~min}$, range 45-58 $\mathrm{min}$ ). The only intraoperative complication was an iatrogenic break during removal of fibrovascular membranes in 1 eye, requiring silicone oil tamponade (patient 1 in Table 1). The remaining 11 eyes were left with a gasfilled vitreous cavity, 10 eyes with $17 \% \mathrm{C}_{3} \mathrm{~F}_{8}$ and 1 eye with $25 \% \mathrm{SF}_{6}$. All sclerotomies were self-sealed without the need of suture placement.

BCVA outcomes are shown in Table 1. Preoperatively, BCVA of 20/400 or better was recorded in only 2 of 12 (16.7\%) eyes. Postoperatively, BCVA improved to $20 / 400$ or better in 11 of $12(91.7 \%)$ eyes at 6 months $(P=0.001)$. At last follow-up, BCVA of 20/400 or better was recorded in 10 of $12(83.3 \%)$, in comparison to $2(16.7 \%)$ eyes at baseline $(P=0.004)$.

Postoperative complications included $\mathrm{VH}$ in 4 eyes (33.3\%), transient ocular hypertension in 3 eyes (25.0\%), and retinal re-detachment in 1 of the eyes with $\mathrm{VH}$ (patient 3 in Table 1). All cases of postoperative $\mathrm{VH}$ were classified as early and resolved within the first month without the need for reoperation. The patient with the detachment achieved anatomic re-attachment following PPV with silicone oil tamponade. Transient ocular hypertension was during the first week in 3 eyes $(25.0 \%$, range $25-36 \mathrm{mmHg}$ ), all of which responded promptly to topical treatment with brinzolamide (1.0\%) every $8 \mathrm{~h}$.

At final follow-up anatomic re-attachment was confirmed in all eyes. Examples of pre- and post-operative ultra-widefield fundus photographs are shown in Fig. 1. In addition, two surgical video files are included as onlineonly material (Additional file 1 and Additional file 2).

\section{Discussion}

The results of the current study suggest that 27-gauge MIVS system is a useful surgical alternative for the management of CTRRD as minimal intraoperative complications occurred and BCVA remained stable or improved in $91.6 \%$ of eyes. Postoperative complications included $\mathrm{VH}$ in $33.3 \%$ of eyes and transient ocular hypertension in $25.0 \%$. Only one patient required a subsequent surgery. At final follow-up anatomic success was confirmed in all eyes.

At present, studies reporting on surgical techniques and outcomes for treating CTRRD include 20-, 23- and 25-gauge systems [8-11]. In 2003, Douglas et al. [8] evaluated the surgical outcomes of 22 eyes with CTRRD who underwent 20-gauge pars plana lensectomy, PPV and SO tamponade. Within one month, $13.6 \%$ of eyes developed IOP $\geq 35 \mathrm{mmHg}$ resulting from silicone oil migration to anterior chamber. At 6 months postoperatively, $\mathrm{BCVA}$ worsened in $27 \%$ of eyes. The rate of reoperation 

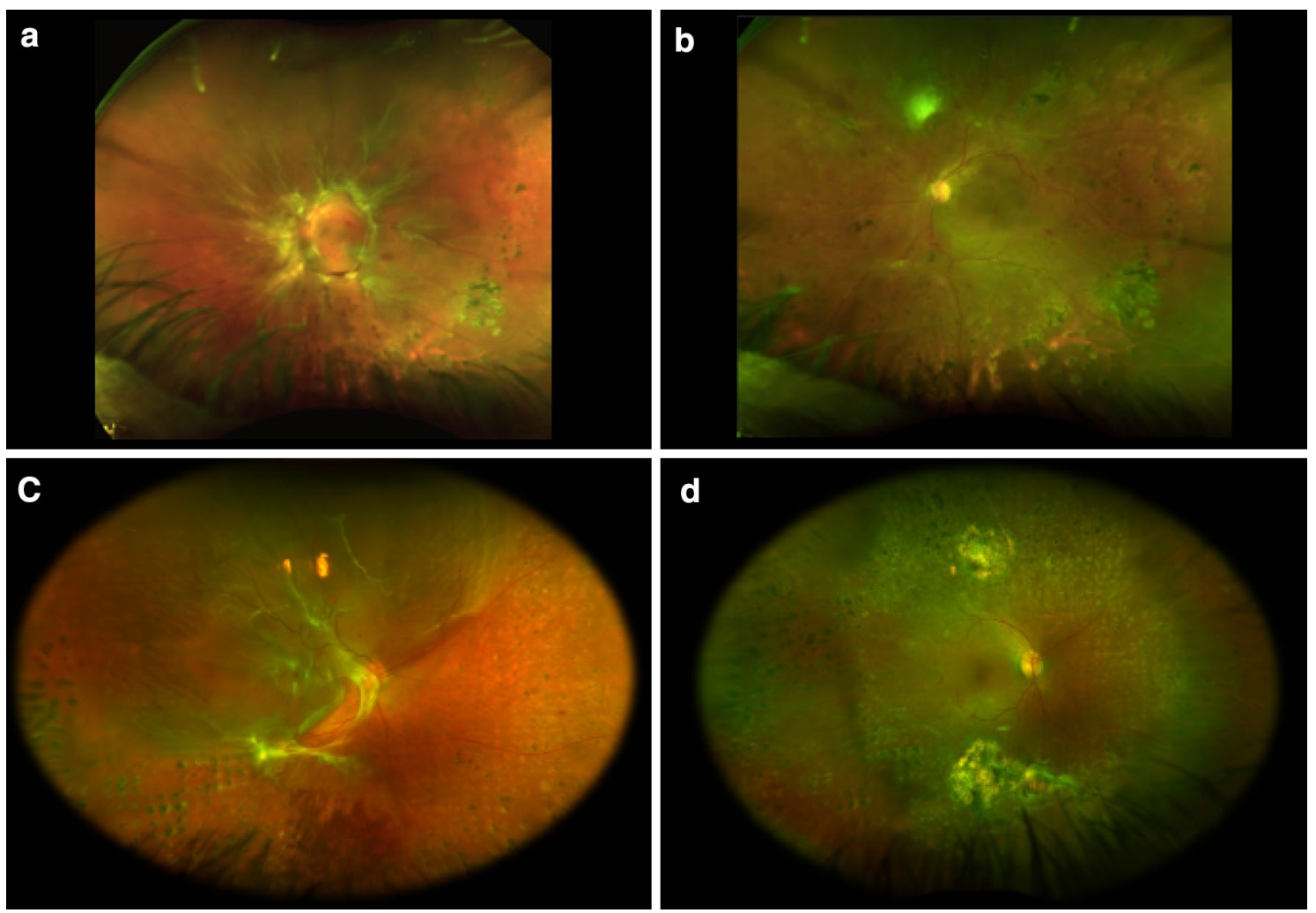

Fig. 1 Case 4 (left eye); a Preoperative ultra-widefield fundus photograph showed combined tractional and rhegmatogenous retinal detachment with fibrovascular proliferation along the arcades; $\mathbf{b}$ postoperative fundus ultra-widefield fundus photograph showed retinal attachment with six months after surgery. Case 7 (right eye); c preoperative ultra-widefield fundus photograph showed combined tractional and rhegmatogenous retinal detachment; $\mathbf{d}$ postoperative fundus ultra-widefield fundus photograph showed retinal attachment 1 year after surgery

for either epiretinal membrane formation or recurrent RD was 63.6\%. Subsequently, in 2008 Yang et al. [9] evaluated the surgical outcomes of 40 eyes with CTRRD who underwent 20-gauge PPV with scleral buckle and, in selected cases, SO tamponade was also used. After 6 month follow-up period, BCVA decreased in $15 \%$ of eyes and the rate of recurrent RD requiring reoperation was $7.5 \%$. Then in 2011, Farouk et al. [10] evaluated the surgical outcomes of 200 eyes with PDR, including 6 eyes with CTTRD. All surgeries were performed using 25-gauge PPV and, in selected cases, either intraocular tamponade with air, $\mathrm{C}_{3} \mathrm{~F}_{8}$ or $\mathrm{SO}$ were used. Sub-analysis limited to patients with CTTRD was only performed to assess for anatomic success 6 months after surgical intervention. In this study, the reoperation rate for CTTRD was $17.0 \%$. More recently, in 2014 Hsu et al. [11] evaluated the surgical outcomes in 57 eyes with CTRRD who underwent 20- or 23-gauge vitrectomy with IVB at the end of surgery. In selected cases one or more of the following surgical strategies were used: pre-operative IVB, scleral buckle, and, gas or SO tamponade. At a mean follow-up of 24.4 months, BCVA worsened in $7.0 \%$ of eyes, the rate of recurrent $\mathrm{RD}$ requiring reoperation was $7.0 \%$ and recurrent $\mathrm{VH}$ was seen in $3.5 \%$ of eyes. In these studies operative time and intraoperative complications were not reported, while in the latter two studies IOP results were not addressed.

In the current study the only intraoperative complication noted was an iatrogenic break in the already detached retina in 1 eye, while postoperative complications included $\mathrm{VH}$, transient ocular hypertension and a recurrent retinal detachment. Similar to the current study findings, other studies reporting surgical outcomes using the 27-gauge PPV system for treating various vitreous, macular and other vitreoretinal diseases have reported no intraoperative complications. Only few postoperative complications have been reported [4-7]. In 2010, Oshima et al. [4] first evaluated the efficiency, safety and feasibility of 27-gauge MIVS in 31 eyes with a variety of vitreoretinal diseases and found that recurrent $\mathrm{VH}$ was the only postoperative complication, only observed in 2 eyes (6.5\%). In 2015 Rizzo et al. [6] evaluated the surgical outcomes of 16 eyes with a variety of posterior segment diseases, and found no postoperative complications. More recently, Khan et al. [7] evaluated the surgical outcomes of 27-gauge vitrectomy in 95 eyes 
with a variety of posterior segment diseases, and found that postoperative complications were limited to recurrent retinal detachment in $10 \%$ of cases with $\mathrm{RD}$, transient ocular hypertension in $8 \%$ of all cases, transient hypotony and VH occuring in 5\% each. Similar to these studies $[4,5]$, postoperative $\mathrm{VH}$ also resolved spontaneously in our study without the need of additional surgical intervention. Because recurrent bleeding in PDR is a well-known finding postoperatively $[11,12]$, we agree with Oshima et al. [4] that $\mathrm{VH}$ in our series could be attributed to our patients' history of PDR rather than the surgical technique used.

In the current series, no cases of significant intraoperative bleeding occurred. Postoperatively, $\mathrm{VH}$ occurred in $33.3 \%$ of cases, all of which were classified as early and none required reoperation. Other studies have reported postoperative VH following PPV for PDR in $12-63 \%$ of cases of which approximately one-third required a second vitrectomy [12-19]. Associated risk factors for postoperative $\mathrm{VH}$ include incomplete preoperative scatter laser photocoagulation, active fibrovascular tissue, phakia, younger age, and hypotony [19-21]. In the current study, all patients who developed early postoperative $\mathrm{VH}$ were phakic, showed active fibrovascular membranes and none experienced ocular hypotony. Preoperative panretinal photocoagulation was not performed due to the risk of contraction of preretinal membranes [22-24], instead it was performed at end of surgery. To reduce the risk of intraoperative bleeding, IVB was injected $3-5$ days prior to surgery in this series, but no more than 5 days to avoid causing fibrovascular contraction and subsequent worsening of the retinal detachment [25-27]. Although the evidence suggests that perioperative IVB helps prevent intraoperative $\mathrm{VH}$ [28-32], the evidence is contradictory for early postoperative VH [33, 34]. Similar to Khuthaila et al. [19] the authors of the current study agree that early postoperative $\mathrm{VH}$ was likely secondary to more aggressive $\mathrm{PDR}$. The absence of late postoperative $\mathrm{VH}$ suggest that 27-gauge PPV with adjuvant IVB facilitated the complete dissection of fibrovascular membranes and that intraoperative panretinal photocoagulation helped achieved regression of neovascularization following surgery.

CTRRD is considered one of the most visually compromising and surgically challenging forms of retinal detachment. Surgical complexity results from severe ocular ischemia causing retinal atrophy and thinness predisposing to iatrogenic breaks $[35,36]$. In the current study, use of the 27-gauge PPV system provided important advantages for avoiding iatrogenic breaks while facilitating removal of fibrovascular tissue from the detached retina, closing retinal breaks, and reattaching the retina. Prior studies have shown that tractional forces are reduced with MIVS [37, 38]. Particularly, Dugel et al. [37] showed that the enhanced 27-gauge probe had the shortest attraction across all cutting speeds and duty cycles followed by the enhanced 25-gauge and 23-gauge probes. Also, the 27-gauge technology provides additional advantages including the ultrahigh-speed vitreous cutter (7500 cuts/ min) with duty cycle controlled by dual pneumatic cutters $[39,40]$, resulting in smaller bit size while simultaneously decreasing vitreous viscosity and maintaining efficient flow rate (Abulon DJK, et al. IOVS 2012;53:ARVOEAbstract36915). Although some concerns regarding the decreased rigidity and lack of dual functionality of the instrumentation have been noted, in our experience the small 27-gauge vitreous cutter introduced between the membranes to dissect and shave the fibrovascular tissue is ideal for treating CTTRD while avoiding iatrogenic breaks.

Limitations of the current study include the small sample size, the lack of a control group undergoing similar surgery with a larger gauge instrumentation and the absence of preoperative fluorescein angiography results. The small sample size could raise concerns regarding the reproducibility of results. However, published studies using 27-gauge technology for treating other complex vitreoretinal cases have reported similar favorable outcomes with only few complications [5, 7]. In addition, the occurrence of CTRRD is declining as diabetic retinopathy is being treated earlier with anti-VEGF agents [41]. Likely, this will limit future studies sample size while making results from smaller sample studies more valuable. In addition, due to the lack of a control group undergoing similar surgery with a large gauge instrumentation, the current study cannot assess the efficacy of 27-gauge MIVS. Finally, routine preoperative fluorescein angiography was not performed. As a result, macular ischemia prior to surgical intervention could not be addressed.

In summary, results of the current study suggest that 27-gauge PPV is a safe and promising surgical technology for treating patients with CTRRD involving the macula associated with PDR. Smaller gauge instruments and higher cutting rates may facilitate the dissection and shaving of fibrovascular membranes, and also may minimize intra- and post-operative complications. Future studies comparing surgical outcomes with larger gauge equivalents for treating CTTRD are needed to assess the advantages and limitations of this technology.

\section{Additional files}

Additional file 1. Surgical video of twenty-seven-gauge vitrectomy for dissecting and shaving fibrovascular tissue in a patient with a combined tractional and rhegmatogenous retinal detachment. Also, shown is this video is removal of subretinal fibrosis.

Additional file 2. Surgical video of twenty-seven-gauge vitrectomy for dissecting and shaving fibrovascular tissue in a patient with a combined tractional and rhegmatogenous retinal detachment. 


\section{Abbreviations}

PPV: pars plana vitrectomy; CTRRD: combined tractional and rhegmatogenous retinal detachments; BCVA: best corrected visual acuity; PDR: proliferative diabetic retinopathy; MIVS: transconjunctival microincision vitrectomy surgery; $\mathrm{VH}$ : vitreous hemorrhage; $\mathrm{SF}_{6}$ : sulfur hexafluoride; $\mathrm{C}_{3} \mathrm{~F}_{8}$ : perfluoropropane; SO: silicone oil; IOP: intraocular pressure; OCT: optical coherence tomography; IVB: intravitreal bevacizumab.

\section{Authors' contributions}

YJCl drafted, revised and submitted the manuscript; MHB collected the data and revised the manuscript. Both authors read and approved the final manuscript.

\section{Author details}

${ }^{1}$ Department of Ophthalmology, Río Piedras Medical Center, University of Puerto Rico, San Juan 00909, Puerto Rico. ${ }^{2}$ Berrocal \& Associates, San Juan, Puerto Rico.

\section{Acknowledgements}

None.

\section{Competing interests}

Dr. María H. Berrocal has the following financial interests or relationships to disclose. Personal fees: Alcon (Fort Worth, Tx) and Allergan (Irving, CA). Dr. Yousef J. Cruz-Iñigo has no financial interests or relationships to disclose.

\section{Availability of data and materials}

The datasets used and/or analyzed during the current study are available from the corresponding author on reasonable request.

\section{Ethics approval and consent to participate}

Not applicable.

\section{Funding/support}

This study did not receive any government and non-government support.

\section{Publisher's Note}

Springer Nature remains neutral with regard to jurisdictional claims in published maps and institutional affiliations.

Received: 31 May 2017 Accepted: 20 August 2017

Published online: 09 October 2017

\section{References}

1. Lakhanpal RR, Humayun MS, de Juan E, et al. Outcomes of 140 consecutive cases of 25-gauge transconjunctival surgery for posterior segment disease. Ophthalmology. 2005;112(5):817-24.

2. Spirn MJ. Comparison of 25,23 and 20-gauge vitrectomy. Curr Opin Ophthalmol. 2009;20(3):195-9.

3. Thompson JT. Advantages and limitations of small gauge vitrectomy. Surv Ophthalmol. 2011;56(2):162-72.

4. Oshima Y, Wakabayashi T, Sato T, Ohji M, Tano Y. A 27-gauge instrument system for transconjunctival sutureless microincision vitrectomy surgery. Ophthalmology. 2010;117(1):93-102.E2.

5. Rizzo S, Barca F, Caporossi T, Mariotti C. Twenty-seven gauge vitrectomy for various vitreoretinal diseases. Retina. 2015;35(6):1273-8.

6. Mitsui K, Kogo J, Kaeda H, Shiono A, Sasaki H, Munemasa Y, Kaoka Y, Takagi H. Comparative study of 27-gauge vs 25-gauge vitrectomy for epiretinal membrane. Eye. 2016;30:538-44.

7. Khan MA, Shahlaee A, Toussaint B, et al. Outcomes of 27 gauge microincision vitrectomy surgery for posterior segment disease. Am J Ophthalmol. 2016;161:36-43.

8. Douglas MJ, Scott IU, Flynn HW Jr. Pars plana lensectomy, pars plana vitrectomy, and silicone oil tamponade as initial management of cataract and combined traction/rhegmatogenous retinal detachment involving the macula associated with severe proliferative diabetic retinopathy. Ophthalmic Surg Lasers Imaging. 2003;34:270-8.
9. Yang CM, Su PY, Yeh PT, Chen MS. Combined rhegmatogenous and traction retinal detachment in proliferative diabetic retinopathy: clinical manifestations and surgical outcome. Can J Ophthalmol. 2008;43(2):192-8.

10. Farouk MM, Naito T, Sayed KM, Negasawa T, Katome T, et al. Outcomes of 25-gauge vitrectomy for proliferative diabetic retinopathy. Graefes Arch Clin Exp Ophthalmol. 2011;249:369-76.

11. Hsu YJ, Hsieh YT, Yeh PT, Huang JY, Yang CM. Combined tractional and rhegmatogenous retinal detachment in proliferative diabetic retinopathy in the anti-VEGF era. J Ophthalmol. 2014;2014:1-11.

12. Yang CM. Surgical treatment for diabetic retinopathy: 5 year experience. J Formos Med Assoc. 1998:97:477-84.

13. Novak MA, Rice TA, Michels RG, Auer C. Vitreous hemorrhage after vitrectomy for Diabetic retinopathy. Ophthalmology. 1984;91:1485-9 [PubMed: 6521989].

14. Schachat AP, Oyakawa RT, Michels RG, Rice TA. Complications of vitreous surgery for diabetic retinopathy II Postoperative complications. Ophthalmology. 1983;90:522-30.

15. Park DH, Shin JP, Kim SY. Comparison of clinical outcomes between 23-gauge and 20-gauge vitrectomy in patients with proliferative diabetic retinopathy. Retina. 2010;30:1662-70.

16. Blankenship GW. Management of vitreous cavity hemorrhage following pars plana vitrectomy for diabetic retinopathy. Ophthalmology. 1986;93(1):39-44.

17. Brown GC, Tasman WS, Benson WE, McNamara JA, Eagle RC Jr. Reoperation following diabetic vitrectomy. Arch Ophthalmol. 1992;110(4):506-10.

18. Han DP, Murphy ML, Mieler WF, Abrams GW. Outpatient fluid air exchange for severe post-vitrectomy diabetic vitreous hemorrhage. Long term results and complications. Retina. 1991;11(3):309-14.

19. Khuthaila MK, Hsu J, Chiang A, DeCroos FC, Milder EA, Setlur V, et al. Postoperative vitreous hemorrhage after diabetic 23-gauge pars plana vitrectomy. Am J Ophthalmol. 2013;155:757-63.

20. Soto-Pedre E, Hernaez-Ortega MC, Vazquez JA. Risk factors for postoperative hemorrhage after vitrectomy for diabetic retinopathy. Ophthalmic Epidemiol. 2005;12(5):335-41.

21. Lee BJ, Yu HG. Vitreous hemorrhage after the 25-gauge transconjunctival sutureless vitrectomy for proliferative diabetic retinopathy. Retina. 2010;30(10):1671-7.

22. Krill AE, Archer DB, Newell FW, et al. Photocoagulation in diabetic retinopathy. Am J Ophthalmol. 1971;72:299-321.

23. Zweng HC, Little HL, Hammond AH. Complications of argon laser photocoagulation. Trans Am Acad Ophthalmol Otolaryngol. 1974;78:0P195-204

24. D'Amico DJ. Diabetic tractional retinal detachments threatening the fovea and panretinal argon laser photocoagulation. Semin Ophthalmol. 1991;6(1):11-8.

25. di Lauro R, De Ruggiero P, di Lauro MT, Romano MR. Intravitreal bevacizumab for surgical treatment of severe proliferative diabetic retinopathy. Graefes Arch Clin Exp Ophthalmol. 2010;248:785-91.

26. Arevalo JF, Maia M, Flynn HW Jr, et al. Tractional retinal detachment following intravitreal bevacizumab (Avastin) in patients with severe proliferative diabetic retinopathy. Br J Ophthalmol. 2008;92:213-6.

27. Oshima Y, Shima C, Wakabayashi T, et al. Microincision vitrectomy surgery and intravitreal bevacizumab as a surgical adjunct to treat diabetic traction retinal detachment. Ophthalmology. 2009;116:927-38.

28. Kamura Y, Sato Y, Deguchi Y, Yagi F. latrogenic retinal breaks during 20-gauge vitrectomy for proliferative diabetic retinopathy. Clin Ophthalmol. 2013;7:29-33.

29. Rizzo S, Genovesi-Ebert F, Di Bartolo E, Vento A, Miniaci S, Williams G. Injection of intravitreal bevacizumab (Avastin) as a preoperative adjunct before vitrectomy surgery in the treatment of severe proliferative retinopathy (PDR). Grafes Arch Clin Exp Ophthalmol. 2008;246:837-42.

30. El-Batarny AM. Intravitreal bevacizumab as an adjunctive therapy before diabetic vitrectomy. Clin Ophthalmol. 2008;2:709-16.

31. Ahmadieh H, Shoeibi N, Entezari M, Monshizadeh R. Intravitreal bevacizumab for prevention of early postvitrectomy hemorrhage in diabetic patients: a randomized clinical trial. Ophthalmology. 2009;116:1943-8.

32. Hernandez-Da Mota SE, Nunez-Solorio SM. Experience with intravitreal bevacizumab as a preoperative adjunct in 23-G vitrectomy for advanced proliferative diabetic retinopathy. Eur J Ophthalmol. 2010;20:1047-52. 
33. Romano MR, Gibran SK, Marticorena J, Wong D, Heimann H. Can a preoperative bevacizumab injection prevent recurrent post vitrectomy vitreous hemorrhage? Eye (Lond). 2009;23:1698-701.

34. Romano MR, Gibran SK, Marticorena J, Wong D, Heimann H. Can a preoperative bevacizumab injection prevent recurrent post vitrectomy vitreous hemorrhage?. Eur J Ophthalmol. 2009;19:618-21 [PubMed: 19551678].

35. Isa SA, Connor A, Habib M, Steel DHW. Comparison or retinal breaks observed during 23 gauge transconjunctival vitrectomy versus conventional 20 gauge surgery for proliferative diabetic retinopathy. Clin Ophthalmol. 2011;5:109-14.

36. Kamura $Y$, Sato $Y$, Deguchi $Y$, Yagi F. latrogenic retinal breaks during 20-gauge vitrectomy for proliferative diabetic retinopathy. Clin Ophthalmol. 2013;7:29-33.
37. Dugel PU, Abulon DJK, Dimalanta R. Comparison of attraction capabilities associated with high-speed, dual-pneumatic vitrectomy probes. Retina. 2015;35(5):915-20.

38. Dugel PU, Zhou J, Abulon DJK, Buboltz DC. Tissue attraction associated with 20-gauge, 23-gauge, and enhanced 25-gauge dual-pneumatic vitrectomy probes. Retina. 2012;32(9):1761-6.

39. Abulon DJK, Buboltz DC. Performance comparison of highspeed dual-pneumatic vitrectomy cutters during simulated vitrectomy with balanced salt solution. TransI Vis Sci Technol. 2015;4(1):6.

40. Abulon DJK. Vitreous flow rates through dual pneumatic cutters: effects of duty cycle and cut rate. Clin Ophthalmol. 2015;9:253-61.

41. Yang CM. Surgical treatment for diabetic retinopathy: 5-year experience. J Formos Med Assoc. 1998;97(7):477-84.

\section{Submit your next manuscript to BioMed Central and we will help you at every step:}

- We accept pre-submission inquiries

- Our selector tool helps you to find the most relevant journal

- We provide round the clock customer support

- Convenient online submission

- Thorough peer review

- Inclusion in PubMed and all major indexing services

- Maximum visibility for your research

Submit your manuscript at www.biomedcentral com/submit 